\title{
Tomato leaf curl Karnataka virus from Bangalore, India, Appears to be a Recombinant Begomovirus
}

\author{
Orawan Chatchawankanphanich and Douglas P. Maxwell
}

Department of Plant Pathology, University of Wisconsin-Madison, 1630 Linden Drive, Madison 53706. Current address of O. Chatchawankanphanich: Plant Genetic Engineering Unit, Kasetsart University, Nakhon Pathom, 73140 Thailand. Accepted for publication 4 March 2002.

\begin{abstract}
Chatchawankanphanich, O., and Maxwell, D. P. 2002. Tomato leaf curl Karnataka virus from Bangalore, India, appears to be a recombinant begomovirus. Phytopathology 92:637-645.

The genome of Tomato leaf curl virus (ToLCV) from Bangalore, India, a whitefly-transmitted geminivirus, was cloned (pIND9) and sequenced. The circular DNA of 2,759 nucleotides (U38239) is organized similarly to that of other begomoviruses with monopartite genomes. Comparison of the nucleotide sequence of pIND9 with other tomato-associated begomoviruses from India (Tomato leaf curl Bangalore virus [ToLCBV, Z48182]) and Tomato leaf curl New Delhi virus-Severe (ToLCNdV-Svr, U15015) showed moderate DNA sequence identities (82 to $87 \%$ ) between capsid protein $(C P)$ genes but low identities (66 to 67\%) for the intergenic regions and the replication-associated protein (Rep) genes (75 to $81 \%$ identity). Phylogenetic trees generated with nucleotide sequences

of the Rep and CP genes of 26 begomoviruses indicated that this ToLCV is distinct from other begomoviruses and that it may be a recombinant virus derived from at least three different viral lineages. Tomatoes (Lycopersicon esculentum) inoculated with the cloned DNA monomer of ToLCV (pIND9) via particle bombardment developed leaf curling and yellowing symptoms. The virus was transmitted by Bemisia tabaci biotype B from tomatoes infected via particle bombardment to healthy tomatoes and by sap inoculation from infected tomatoes to tomato, Nicotiana benthamiana and $N$. tabacum. This ToLCV is a distinct member of the genus Begomovirus from India that differs from the previously characterized Tomato leaf curl Sadasivanagar virus isolate Bangalore 1 (L12739), ToLCBV (Z48182), ToLCBV isolate Bangalore 4 (AF165098), and the bipartite ToLCNdV (U15015, U15016). Thus, this ToLCV is named Tomato leaf curl Karnataka virus (ToLCKV).
\end{abstract}

Geminiviruses are a group of plant viruses that have circular single-stranded DNA genomes encapsidated within twinned particles. They are divided into four genera based on genome organization, host range, and insect vector $(16,30)$. The genus Begomovirus (formerly subgroup III geminiviruses) is composed of whitefly-transmitted geminiviruses that generally have a bipartite genome consisting of DNA-A and DNA-B components that infect dicotyledonous hosts $(16,30)$. Several monopartite begomoviruses that infect dicotyledonous plants have also been characterized ( 7 , $15,21,23)$

Tomato-infecting geminiviruses cause significant losses in tomato production in many tropical and subtropical countries (5, 10,26). These viruses are transmitted by the whitefly Bemisia tabaci (Genn.), a species complex. Tomato-infecting begomoviruses cause a range of symptoms and may have either monopartite or bipartite genomes. Those with monopartite genomes originated in the Eastern Hemisphere (e.g., Australia [7], Israel [2,23], and Sardinia [15]) and one of these, Tomato yellow leaf curl virus (TYLCV), has been introduced into the Western Hemisphere (26). Bipartite begomoviruses infect tomatoes in Northern India (24) and Thailand (28), as well as in many countries of the Western Hemisphere (26).

Tomato leaf curl virus (ToLCV) causes severe damage to tomato crops in India and induces curling and twisting of the leaves followed by chlorosis. Tomato leaf curl disease was first reported by Vasudeva and Sam Raj (35). Reddy et al. (27) sub-

Corresponding author: D. P. Maxwell; E-mail address: dpm@plantpath.wisc.edu

Tomato leaf curl Karnataka virus isolate Bangalore 2 has been deposited as GenBank Accession No. U38239.

Publication no. P-2002-0416-01R

(C) 2002 The American Phytopathological Society divided the ToLCV isolates from tomatoes collected in Southern India into five strains according to symptoms induced in tomato and indicator hosts following whitefly transmission studies. Muniyappa et al. (20) collected infected tomatoes showing leaf curl symptoms from Karnataka State, India, and designated the stock culture as Bangalore Indian tomato leaf curl virus (ITmLCV). Whiteflies readily transmitted ITmLCV to tomato, Nicotiana tabacum cv. Samsun NN, and Datura stramonium. Recently, two Bangalore isolates of ITmLCV have been partially characterized $(13,21)$. One isolate is now designated Tomato leaf curl Bangalore virus (ToLCBV, assession no. Z48182; Table 1 provides begomovirus acronyms [8]) and its genome is similar in organization to that of other monopartite begomoviruses from the Eastern Hemisphere (23). No information on the infectivity of the cloned ToLCBV DNA or the presence of a DNA-B component was reported. The other isolate has a monopartite genome (AF165098) (21) and is designated ToLCBV-[Bangalore 4] (ToLCBV-[Ban4]). Yet another begomovirus from Northern India, Tomato leaf curl New Delhi virus (ToLCNdV, assession nos. U15015 and U15016) (24), has a bipartite genome, and both components are required for symptom development and systemic movement. Here we describe another begomovirus isolate from tomatoes with leaf curl symptoms from Bangalore, India. This begomovirus is monopartite and sap transmissible to tomato and Nicotiana spp. It is given the name Tomato leaf curl Karnataka virus (ToLCKV).

\section{MATERIALS AND METHODS}

Cloning of the viral genome. Tomatoes (Lycopersicon esculentum) with leaf curling and yellowing symptoms were collected by S. J. Singh from a severely diseased field near the Indian Institute of Horticultural Research, Bangalore, Karnataka State, India, in 1992 and 1993. Leaf tissues were air dried and sent to 
D. P. Maxwell, University of Wisconsin, Madison. DNA was extracted from these dried leaves by the Dellaporta method (6), and polymerase chain reaction (PCR) was used to amplify various geminiviral DNA fragments (29). With the degenerate primer pair PAL1v1978 and PAR1c715 (29), a 1.5-kb fragment, which included part of the replication-associated protein (Rep) gene, common region, and part of the capsid protein $(C P)$ gene, was cloned (pIND16) and sequenced. A single HindIII site was present in this viral fragment and was located in the promoter region for the $V 2$ gene. Overlapping PCR primers that contained a HindIII restriction site (underlined) near their $5^{\prime}$ ends, PINDc1 (5' TTAAAAGCTTGAGCGCGTCATGTG $3^{\prime}$ ) and PINDv2 (5' GAGTAAGCTTATTTGTTTTGTGGT $3^{\prime}$ ), were designed for use in obtaining a fulllength clone. The full-length DNA-A genome was then constructed from two PCR-amplified DNA fragments: a 2.2-kb fragment amplified with primer pair PINDc1/PAR1v722 (5' ATATCTGCAGGGNAARATHTGGATGGA $3^{\prime}$ ) and a 2.0 -kb fragment amplified with primer pair PINDv2/PAL1c1960 (5' TGGACTGCAGACNGGNAARACNATGTGGGC 3'). PAR1v722 and PAL1c1960 are additional degenerate PCR primers designed from the sequence of the $C P$ gene and the Rep gene of different begomoviruses, respectively (4). Restriction enzyme digestion analysis revealed a single SalI site located within the $\operatorname{Tr} A P$ gene in the clones of each of the two PCR fragments. These two PCR fragments also had only the one naturally occurring HindIII site, which was present in the overlapping PCR primer pair. Thus, HindIII and SalI were used for cloning the full-length DNA-A. The two PCR fragments were digested with HindIII and SalI and separately cloned into the pBluescript II KS (+) vector (Stratagene Inc., La Jolla, CA). To obtain a full-length clone of DNA-A, a 1.3-kb DNA fragment was excised by HindIII/KpnI digestion from the recombinant plasmid pINDC1, which contained the 2.2-kb PCR fragment amplified with the primer pair PINDc1/PAR1v722. A second 1.5-kb DNA fragment was obtained by HindIII/XhoI digestion of the recombi- nant plasmid pINDV1, which contained the 2.0-kb PCR fragment generated with the primer pair PINDv2/PAL1c1960. The KpnI and $X h o I$ sites are in the multiple cloning site of the vector. These two digested fragments were ligated into the $K p n \mathrm{I} / \mathrm{XhoI}$-digested pBluescript II KS (+) vector, and the resulting recombinant plasmid pIND9 was selected and used for infectivity and whitefly transmission experiments. The putative full-length DNA-A was released from pIND9 by digestion with SalI, and this DNA-A would have the single naturally occurring HindIII site. To confirm that the full-length DNA-A in pIND9 represented a naturally occurring DNA component, two independent clones were made from DNA fragments obtained by PCR amplification from the Dellaporta DNA extract used to obtain the fragments of the fulllength DNA-A clone. Two PCR primer pairs were designed from the sequence of pIND9 to amplify fragments that would include the HindIII site (pIND-H) and SalI site (pIND-S), respectively, and at least 200 nucleotides flanking the restriction sites. The viral inserts of plasmids pIND-H and pIND-S were sequenced and the sequences were identical to corresponding regions of the viral insert in pIND9.

Infectivity of cloned DNA. Three tomato cultivars, Flora Dade, Hayslip, and Geneva 80, were used for infectivity tests by inoculation with a particle bombardment method (9). The inoculum was the monomer excised from pIND9 by digestion with SalI. The plasmid DNA was prepared with a modified alkaline lysis method (31).

To prepare tomato seedlings for inoculation by particle bombardment, tomato seeds were surface disinfected by soaking in $33 \%$ bleach ( $2 \%$ sodium hypochlorite) for $5 \mathrm{~min}$, washed with sterilized water five times for $30 \mathrm{~s}$ each time, placed on $3 \mathrm{MM}$ Whatman filter paper, and kept at $28^{\circ} \mathrm{C}$ in the dark for 4 days. Seedlings with a 1.5 to $2.0 \mathrm{~cm}$ radicle were placed on $12 \%$ xanthan gum in a 5-cm-diameter petri dish. One microgram of SalIdigested pIND9 was used to coat $2.5 \mathrm{mg}$ of gold particles (1 to

TABLE 1. Begomoviruses used in sequence analysis and phylogenetic tree relationships

\begin{tabular}{|c|c|c|}
\hline Name $^{\mathrm{a}}$ & Accession number & Abbreviation \\
\hline African cassava mosaic virus-Kenya & J02057 & ACMV-KE \\
\hline African cassava mosaic virus-[Nigeria] & X17095 & ACMV-[NG] \\
\hline Bhendi yellow vein virus-India & AF241479 & BYVV \\
\hline China rose geminivirus-Pakistan[P31] & AJ270864 & Crgv-PK[P31] \\
\hline Cotton leaf curl Multan virus-Faisalabad2[62] & AJ002449 & CLCuMV-Fai2[62] \\
\hline Indian cassava mosaic virus & $\mathrm{Z} 24758$ & ICMV \\
\hline Mungbean yellow mosaic virus & D14703 & MYMV \\
\hline Papaya leaf curl virus-India & Y15934 & $\mathrm{PaLCuV}$ \\
\hline Tobacco geminivirus-China & AF240675 & Tgv-CN \\
\hline Tobacco geminivirus-Pakistan[P27] & $\mathrm{AJ} 270864$ & Tgv-PK[P27] \\
\hline Tomato leaf curl Bangalore virus & Z48182 & ToLCBV \\
\hline Tomato leaf curl Bangalore virus-[Ban4] & AF165098 & ToLCBV-[Ban4] \\
\hline Tomato leaf curl Bangladesh virus & AF188481 & ToLCBDV \\
\hline Tomato leaf curl Karnataka virus-[Ban2] & U38239 & ToLCKV-[Ban2] \\
\hline Tomato leaf curl Laos virus & AF195782 & ToLCLV \\
\hline Tomato leaf curl Myanmar virus & AF206774 & ToLCMV \\
\hline Tomato leaf curl New Delhi virus-[Lucknow] & Y16421 & ToLCNdV-[Luc] \\
\hline Tomato leaf curl New Delhi virus-Severe & U15015 & ToLCNdV-Svr \\
\hline Tomato leaf curl New Delhi virus-Mild & U15016 & ToLCNdV-Mld \\
\hline Tomato leaf curl Sadasivanagar virus-[Ban1] & L11746, L12738, L12739 & ToLCSadV-[Ban1] \\
\hline Tomato leaf curl Sri Lanka virus & AF274349 & ToLCLKV \\
\hline Tomato leaf curl Taiwan virus & U88692 & ToLCTWV \\
\hline Tomato leaf curl virus-Australia & S53251 & ToLCV \\
\hline Tomato mottle virus & Personal communication ${ }^{\text {b }}$ & ToMoV \\
\hline Tomato mosaic Havana virus & Y14874 & ToMHV \\
\hline Tomato yellow leaf curl virus-[Dominican Republic] & AF024715 & TYLCV-[DO] \\
\hline Tomato yellow leaf curl virus-[Iran] & AJ132711 & TYLCV-[IR] \\
\hline Tomato yellow leaf curl virus & X15656 & TYLCV \\
\hline Tomato yellow leaf curl virus-Mild & X76319 & TYLCV-Mld \\
\hline Tomato yellow leaf curl Sardinia virus & X61153 & TYLCSV \\
\hline Tomato yellow leaf curl Sardinia virus-Sicily & Z28390 & TYLCSV-Sic \\
\hline Tomato yellow leaf curl Thailand virus-[2] & AF141922 & TYLCTHV-[2] \\
\hline
\end{tabular}

a Virus names are those proposed by Fauquet et al. (8).

b Personal communication from R. L. Gilbertson. 
$3 \mu \mathrm{m}$ in diameter, Bio-Rad Laboratories, Hercules, CA) in $25 \mathrm{mM}$ spermidine by adjusting the solution to $0.62 \mathrm{M} \mathrm{CaCl}_{2}$. The supernatant was discarded, and the pellet was resuspended in $2.5 \mathrm{ml}$ of ethanol. After a brief sonication, aliquots of the gold-ethanol suspension $(320 \mu \mathrm{l})$ were placed on 18-mm-square aluminized Mylar sheets (Bio-Rad Laboratories), the gold particles were allowed to settle, the ethanol was removed, and the sheets were air dried. Tomato seedlings were inoculated by particle bombardment as described by McCabe et al. (17). Inoculated seedlings were planted in Jiffy mix and kept in a growth chamber at $28^{\circ} \mathrm{C}$ with alternating $14 \mathrm{~h}$ light and $10 \mathrm{~h}$ dark periods for at least 10 weeks. Symptom development was recorded periodically starting 15 days after inoculation. The presence of ToLCKV DNA-A in newly emerged leaves of inoculated tomato seedlings was detected by PCR with the ToLCKV primer pair PINDv1 (5' TGAGCTGCAGTGATGAGTTCCC $3^{\prime}$ ) and PINDc2300 (5' TTCCATCCAAACTTCCAGGG 3').

The infectivity of the virus derived from the cloned DNA in pIND9 on various host plants was determined by sap inoculation of tomatoes, N. benthamiana, N. glutinosa, N. tabacum, Chenopodium amaranticolor, D. stramonium, Petunia hybrida, bean (Phaseolus vulgaris), mungbean (Vigna subterranea), pepper (Capsicum frutescens), and soybean (Glycine max). Sap inoculum was prepared by grinding symptomatic leaf tissue from tomatoes, which were infected after particle bombardment with the cloned viral DNA, in $0.5 \mathrm{M}$ phosphate buffer, $\mathrm{pH} 8.0$ ( $1 \mathrm{~g}$ of tissue per $2 \mathrm{ml}$ of buffer). Young leaves of test plants were lightly dusted with Carborundum, rubbed with sap inoculum using a cotton wrapped stick (Q-tip), maintained in a growth chamber at $28^{\circ} \mathrm{C}$ for 2 months, and periodically inspected for symptom development. Viral DNA in newly emerged leaves was detected by PCR with the ToLCKV primers as described previously.

Equivalent symptomatic tomato plants were used as the source of inoculum for the whitefly transmission experiments. Healthy tomatoes were grown in a growth chamber. Whiteflies (B. tabaci biotype B) (18) were maintained on tobacco plants ( $N$. tabacum) grown in whitefly-proof screened cages in a controlled temperature room at $30^{\circ} \mathrm{C}$ with an 18 -h photoperiod and $\approx 16 \%$ relative humidity (18). Twenty adult whiteflies were fed on infected tomatoes and 20 others on healthy tomatoes in separate whitefly- proof screened cages. After 72 h, 10 whiteflies from each treatment were collected and stored at $-80^{\circ} \mathrm{C}$ for PCR detection of viral DNA. The remaining whiteflies from each treatment were transferred to separate cages containing five healthy tomato seedlings each. After $72 \mathrm{~h}$, they were killed with acephate (18). These whitefly-exposed tomatoes were held in a growth chamber with a $26^{\circ} \mathrm{C}$ light period (14-h photoperiod, $\approx 310 \mu \mathrm{E}$ ) and $2^{\circ} \mathrm{C}$ dark period for at least 4 weeks and observed for symptom development. ToLCKV DNA was detected both in tomato leaves and in adult whiteflies by PCR with the ToLCKV primer pair, PINDv1 and PINDc2300. These whitefly transmission experiments were repeated three times.

Sequence analysis. Both strands of the viral DNA insert in pIND9 were sequenced with the dideoxynucleotide chain termination method (32) and a DNA sequencing kit (T7 Sequenase 2.0; Amersham, Piscataway, CA) according to the manufacturer's instructions. Only one strand of the inserts in pIND-H and pIND$\mathrm{S}$ were sequenced. Sequencing primers were the M13 universal primers and specific primers designed from partial sequences of the viral inserts. Sequence data were analyzed with software of the Wisconsin Package version 9.0, Genetic Computer Group (GCG), Madison, WI. Because the names of geminivirus species are problematic, those published by Fauquet et al. (8) have been used (Table 1). The nucleotide sequence of the viral DNA insert in pIND9 (U38239) was compared with those of other begomoviruses available in GenBank (Table 1). Relationships among these geminiviruses were examined by comparing nucleotide se-

TABLE 3. Genome organization for Tomato leaf curl Karnataka virus

\begin{tabular}{lccc}
\hline $\begin{array}{l}\text { Open } \\
\text { reading frame }\end{array}$ & Nucleotide & $\begin{array}{c}\text { Number of } \\
\text { amino acids }\end{array}$ & $\begin{array}{c}\text { Molecular } \\
\text { mass (kDa) }\end{array}$ \\
\hline$C P$ or $V 1$ & $304-1074$ & 256 & 28 \\
$V 2$ & $144-500$ & 118 & 13 \\
Rep or $C 1$ & $1523-2608$ & 359 & 40 \\
TrAP or $C 2$ & $1216-1620$ & 134 & 15 \\
$R E n$ or $C 3$ & $1071-1475$ & 133 & 15 \\
$C 4$ & $2158-2451$ & 85 & 11 \\
\hline
\end{tabular}

${ }^{\text {a }} C P=$ capsid protein; $\operatorname{Rep}=$ replication-associated protein; $\operatorname{Tr} A P=\operatorname{tran}$ scriptional activator protein; Ren $=$ replication protein enhancer.

TABLE 2. Infection of selected plants with cloned DNA of Tomato leaf curl Karnataka virus (ToLCKV) from recombinant plasmid pIND9 by inoculation with a particle bombardment method and by mechanical inoculation with sap from tomatoes inoculated with ToLCKV DNA

\begin{tabular}{|c|c|c|c|}
\hline Plant & Infectivity $^{\mathrm{a}}$ & Symptoms & Days to symptoms ${ }^{b}$ \\
\hline \multicolumn{4}{|l|}{ Biolistic inoculation $^{\mathrm{c}}$} \\
\hline \multicolumn{4}{|l|}{ Tomato (Lycopersicon esculentum) } \\
\hline 'Flora Dade' & $12 / 20$ & Leaf curling, yellowing & 45 \\
\hline 'Geneva 80' & $15 / 20$ & Leaf curling, yellowing & 45 \\
\hline \multicolumn{4}{|l|}{ Sap inoculation $^{\mathrm{d}}$} \\
\hline \multicolumn{4}{|l|}{ Tomato (L. esculentum) } \\
\hline Nicotiana benthamiana & $18 / 20$ & Yellowing, stunting & $10-14$ \\
\hline N. glutinosa & $0 / 20$ & None & $\ldots$ \\
\hline N. tabacum & $15 / 20$ & Mosaic & $10-14$ \\
\hline Chenopodium amaranticolor & $0 / 20$ & None & $\ldots$ \\
\hline Datura stramonium & $0 / 20$ & None & $\ldots$ \\
\hline Petunia hybrida & $0 / 20$ & None & $\ldots$ \\
\hline
\end{tabular}

${ }^{a}$ Number of plants with symptoms/number of plants inoculated. All plants were maintained in a growth chamber at $28^{\circ} \mathrm{C}$.

${ }^{b}$ Length of time for symptom development after inoculation. Number indicates the number of days before symptoms were first observed. Viral polymerase chain reaction fragment was detected only in DNA extracts from plants with symptoms. Plants were observed for 10 weeks.

${ }^{\mathrm{c}}$ Inoculum was the excised monomeric full-length insert of pIND9 (SalI digestion).

${ }^{\mathrm{d}}$ Inoculum was sap prepared in phosphate buffer from symptomatic tomato plants cv. Flora Dade inoculated by particle bombardment with ToLCKV DNA. 
quences of the Rep gene, the $C P$ gene, the intergenic region ([IR] $5^{\prime}$ end of the IR, which includes the nucleotides from the start codon of the Rep gene to the stem-loop motif), and the entire sequence of DNA-A using the GAP program of GCG with a gap weight of 5 and a gap length weight of 0.3 . Identities along the length of the sequence were prepared with the GCG software, PLOTSIMILARITY, for pairwise comparisons (window $=20$ ) of several potential recombinant viruses. The BLAST program (National Center for Biotechnology Information [NCBI], Bethesda, MD) was used to search the GenBank database for sequences most identical to various regions of ToLCKV (pIND9) (1). Phylogenetic analyses were done by a cladistic parsimony method with PAUP version 3.1 developed by D. L. Swofford (Illinois Natural History Survey, Champaign). Optimum trees were obtained with the Heuristic method with the branch-swapping option. One

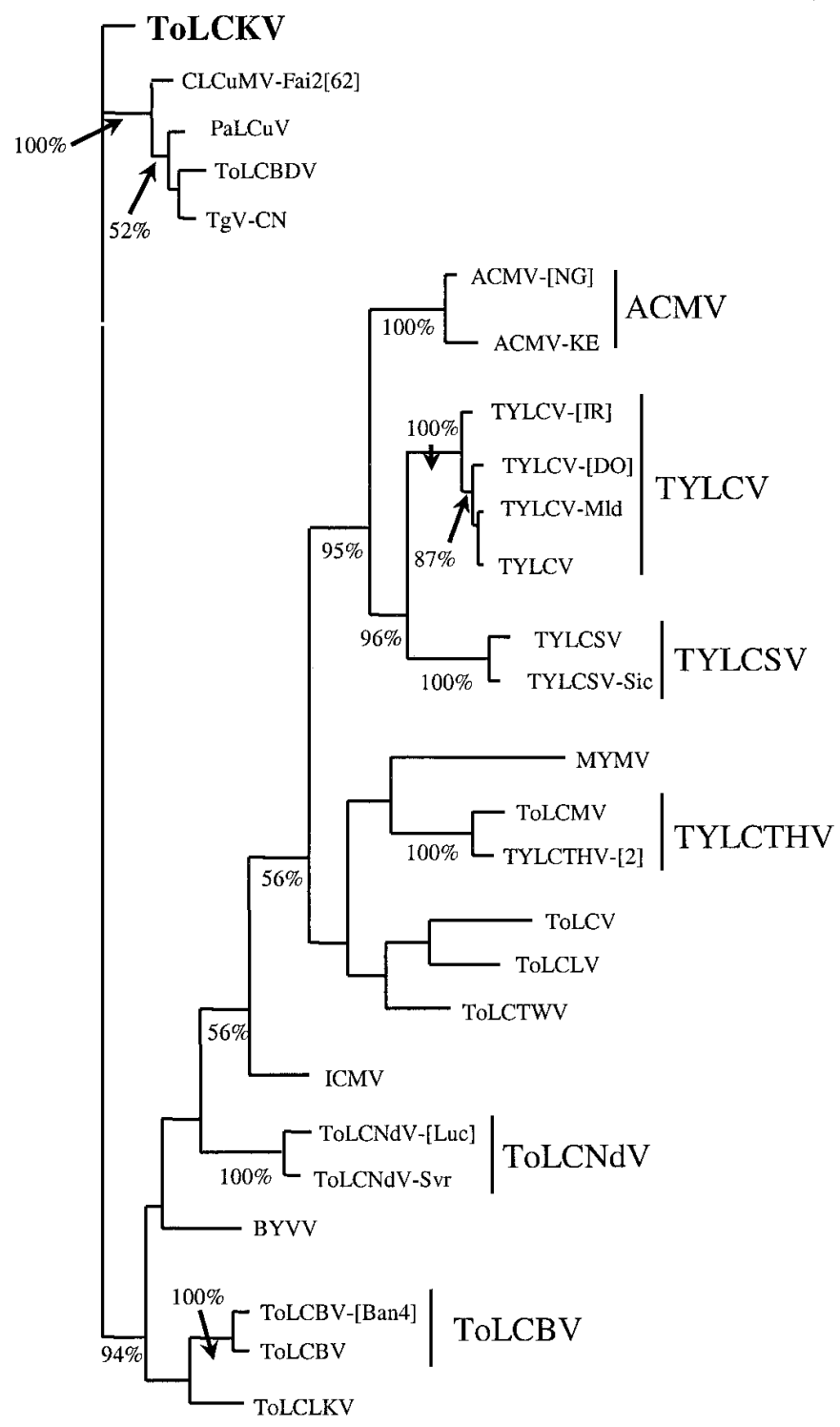

- 50 nt changes

Fig. 1. Phylogenetic tree showing the relationship of Tomato leaf curl Karnataka virus (ToLCKV) isolate Bangalore 2 with 26 begomoviruses from the Eastern Hemisphere based on the alignment of nucleotide sequences of the capsid protein gene. Tree was created by PAUP program version 3.1. The percentage of trees having the given branch is shown below the horizontal line. Vertical distances are arbitrary and the horizontal distances are in proportion to the number of nucleotide differences between branch nodes. Abbreviations and GenBank accession numbers of viruses are provided in Table 1. hundred bootstrap replications were performed for each data set to place confidence estimates on groups contained in the most parsimonious tree. Begomoviruses were assigned to a cluster when they occurred in the same branch $>50 \%$ of the time in the bootstrap replication analysis. Alignments of nucleotides of the Rep and $C P$ genes were prepared by first constructing the alignments based on conserved amino acid sequences, and these amino acid alignments were used to create the nucleotide alignments for these two genes. In addition, the alignment of nucleotides of DNA-A of the Asian begomoviruses, including ToLCKV, is available at the Gemininet website. This alignment was used to construct phylogenetic relationships with the same PAUP software parameters listed above. The detection of possible recombination events among geminiviruses involved a statistical approach (GENECONV) used for detection of gene conversions that was subsequently applied to geminiviruses (25) to detect recombination. Nonoverlapping recombination regions were assigned a $P$ value, and those with $P<0.001$ were considered significant, when a "g scale" value of 1 was used. The alignment of the Rep gene, which was used for construction of a phylogenetic tree, was used with the GENECONV software to detect possible recombination regions.

\section{RESULTS}

Cloning, infectivity, and whitefly transmission. The same name, ToLCV, has been used to describe different tomato-infecting geminiviruses from India and other geographical locations $(4,13,21,24)$. For clarity and uniformity, the virus isolate characterized in this study is named ToLCKV isolate Bangalore $2(8,30)$ to distinguish it from the other tomato-associated geminiviruses from Bangalore, India, including ToLCBV described by Hong and Harrison (13), Tomato leaf curl Sadasivanagar virus-[Ban1] (ToLCSadV-[Ban1]) described by Chatchawankanphanich et al. (4), and ToLCBV-[Ban4] (AF165098) described by Muniyappa et al. (21). The results from restriction enzyme digestions of the two cloned PCR fragments obtained with PCR primer pairs PINDc1/PARv722 and PINDv2/PAL1c1960 indicated that the genome of ToLCKV contains one HindIII and one SalI site. A fulllength clone (pIND9) of a DNA-A-like component of ToLCKV was then constructed from these two PCR-amplified DNA fragments. The integrity of the full-length clone (pIND9) was verified by sequencing at least 500 nucleotides of two independent PCRamplified DNA fragments that are contained in clones pIND-H and pIND-S. These sequence data confirmed that the HindIII and SalI sites were unique and that the sequences flanking these restriction sites were identical to those in pIND9. The infectivity of cloned ToLCKV DNA was tested by the inoculation of tomato seedling radicles with particle bombardment of SalI-digested pIND9. Approximately 45 days after inoculation, 55, 60, and 75\% of the inoculated tomato seedlings of cvs. Hayslip, Flora Dade, and Geneva 80, respectively, developed symptoms of leaf curling and yellowing (Table 2). When shoots from these symptomatic tomatoes were grafted onto healthy cv. Geneva 80 tomatoes, the latter developed similar leaf curling and yellowing symptoms within 10 to 14 days. The presence of ToLCKV DNA in symptomatic plants was confirmed by PCR with the ToLCKV primer pair (PINDv1/PINDc2300) (data not shown). Plants mock-inoculated with gold particles did not develop symptoms and no viral DNA was detected by PCR. Tomato plants inoculated with sap prepared from symptomatic tomatoes developed leaf curling and yellowing symptoms 30 to 40 days after inoculation. Sap-inoculated $N$. benthamiana plants developed yellowing symptoms within 7 days and were stunted by 14 days, whereas $N$. tabacum plants developed mosaic symptoms, but not leaf curling and yellowing, 10 to 14 days after inoculation. ToLCKV was not sap-transmitted to $N$. glutinosa, Chenopodium amaranticolor, D. stramonium, petunia, bean, mungbean, soybean, or pepper plants (Table 2). In addition, both nonexcised and SalI-linearized pIND9 DNA was 
infectious when rub-inoculated on tomato plants (cv. Geneva 80), and leaf curl symptoms developed on these plants 40 days after inoculation (data not shown).

Whiteflies of biotype B (18) were used to transmit ToLCKV from cv. Flora Dade tomatoes inoculated by particle bombardment to healthy tomato plants. Twelve of the fifteen plants exposed to viruliferous whiteflies developed leaf curling and yellowing symptoms within 35 days, and PCR with the ToLCKV primers (PINDv1/PINDc2300) yielded the expected size of DNA fragment from DNA extracts prepared from the symptomatic tomatoes and the whiteflies used to inoculate them. No symptoms were observed on the tomato plants exposed to whiteflies that had been fed on healthy tomatoes, and no viral DNA was detected by PCR in the DNA extracts from these symptomless tomatoes or from the whiteflies.

Genome oganization. Because severe symptoms developed in tomatoes following particle bombardment with pIND9, and the virus was whitefly-transmissible, it was concluded that ToLCKV is a monopartite geminivirus. The monopartite nature of ToLCKV established that it is different from the bipartite ToLCNdV from northern India (24).

The complete sequence of the full-length viral DNA insert in pIND9 is 2,759 nucleotides (U38239). The genome organization is similar to that of all other monopartite begomoviruses, which have four open reading frames (ORFs) on the complementary sense strand and two ORFs on the viral sense strand that encode for predicted proteins $\geq 10 \mathrm{kDa}$ and a $5^{\prime}$ IR (166 nucleotides) (Table 3). On the viral sense strand, the $C P$ is encoded by the $C P$ (V1) gene that is partially overlapped by the small $V 2$ ORF, which encodes a 13-kDa protein. The four ORFs on the complementary strand are designated as Rep $(C 1)$ gene (40 kDa), TrAP (C2) gene (15 kDa), REn (C3) gene (15 kDa), and C4 ORF (11 kDa). The IR that is between the start codon of the Rep gene and the $V 2$ gene contains the nanonucleotide TAATATTAC, which has the DNAnicking site for the initiation of viral strand replication (11) in the loop of a potential hairpin structure. In the $5^{\prime}$ portion of the IR $\left(5^{\prime}\right.$ $\mathrm{IR}=$ common region $(\mathrm{CR})$, which refers to a 166-bp region that has the stem-loop motif at its $3^{\prime}$ end) the sequence ATCGGTGT at nucleotides 2622-2629 is repeated at nucleotides 2649-2656, and these potential Rep protein-binding sites are located between the TATA box (nucleotides 2669-2272) and the start codon of the Rep gene (11). Transcription of the genes of geminiviruses is bidirectional $(19,34)$, and polyadenylation signals (AATAAA) are located at the convergence of the $C P$ gene and REn genes of ToLCKV.

Sequence comparison. Five approaches were used to determine the relationships between ToLCKV and other begomoviruses. These involved BLAST searches with the DNA sequence at NCBI (Bethesda, MD), pairwise sequence comparisons with the GAP software of the GCG program, PLOTSIMILARITY comparisons with the software of the GCG program, a search for possible recombination events with GENECONV software, and construction of phylogenetic trees for the full-length DNA, the $C P$ and Rep genes, and for the $\mathrm{C}$ terminus (nucleotides 1523 to 2153 of ToLCKV) and N terminus of the Rep gene (nucleotides 2158 to 2608 of ToLCKV). The results from the BLAST search with the entire sequence of ToLCKV showed that it is most identical ( 85 to $88 \%$ nucleotide identity for more than 1,900 nucleotides) to the DNA-A of Tomato leaf curl Bangladesh virus-BD2 from Bangladesh (ToLCBDV, AF188481) (36), a tobacco geminivirus isolate Y1 from Yunnan, China (Tgv-CN, AF240675), Papaya leaf curl virus from India (PaLCuV, Y15934), Cotton leaf curl Multan virus isolate clc806b from Pakistan (CLCMV-Fai2[62], AJ002449), and ToLCBV from Bangalore, India (Z48182) (13). Pairwise comparisons, made by the GAP software of GCG, of ToLCKV with the begomoviruses identified by the BLAST analysis as most identical to ToLCKV gave the highest nucleotide identity, $85 \%$, with ToLCBDV and Tgv-CN. The two other tomato-associated begomovirus isolates from Bangalore, ToLCBV-
[Ban4] (AF165098) (21) and ToLCBV, had nucleotide identities of 84 and $82 \%$, respectively. As expected, a phylogenetic analysis with the alignment from Gemininet of 37 Asian begomoviruses placed ToLCKV and ToLCBDV in a large clade along with Tomato leaf curl Myanmar virus (ToLCMV), PaLCuV, ToLCBV, and ToLCBV-[Ban4] (data not shown, Gemininet website).

A phylogenetic tree derived from the $C P$ gene nucleotide sequences for 26 Eastern Hemisphere begomoviruses placed ToLCKV in a clade of five viruses (Fig. 1). ToLCKV was the sole member of one branch and the other four viruses, CLCuMVFai2[62], PaLCuV, ToLCBDV, and a Tgv-CN, formed a closely related group. These five viruses were clearly separated from the clade containing the two other tomato-associated begomoviruses from Bangalore, ToLCBV and ToLCBV-[Ban4], which appeared closely related. When the alignment of the Rep gene nucleotide sequences was used to create a phylogenetic tree (Fig. 2), some of

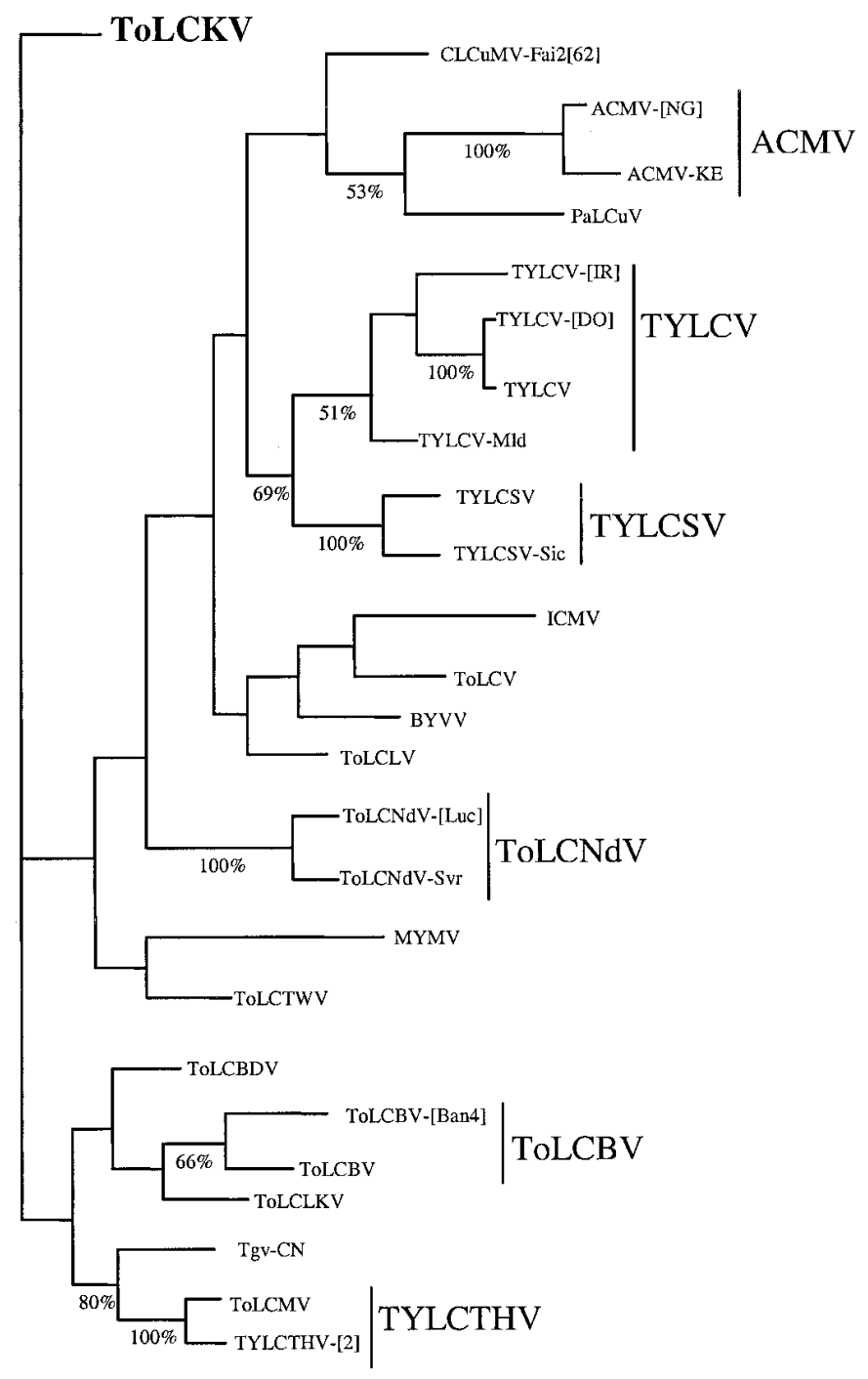

$50 \mathrm{nt}$ changes

Fig. 2. Phylogenetic tree showing the relationship of Tomato leaf curl Karnataka virus (ToLCKV) isolate Bangalore 2 with 26 begomoviruses from the Eastern Hemisphere based on the alignment of nucleotide sequences of the replication-associated protein gene. Tree was created by PAUP program version 3.1. The percentage of trees having the given branch is shown below the horizontal line. Vertical distances are arbitrary, and the horizontal distances are in proportion to the number of nucleotide differences between branch nodes. Abbreviations and GenBank accession numbers of viruses are provided in Table 1. 
the viruses were placed in clusters different from those in the $C P$ gene phylogenetic tree. In particular, the five viruses placed in the clade with ToLCKV in the $C P$ gene phylogenetic tree were now placed in separate clades, and ToLCKV was not closely associated with any virus. Phylogenetic trees derived from the nucleotide alignments of the $C P$ and Rep genes and including the two Western Hemisphere begomoviruses, Tomato mottle virus and Tomato mosaic Havana virus (Y14874), showed the same relationships between ToLCKV and the other begomoviruses (data not shown).

Because ToLCKV is grouped with different begomoviruses depending on the gene used for the tree construction, it is possible that ToLCKV might be a recombinant virus. This possibility was examined by completing individual BLAST searches with sequences of ToLCKV for each of the viral genes, the $5^{\prime}$ IR (common region), and the promoter region for the $C P$ gene. From these BLAST searches, the begomoviruses with the highest percent identities were then used in individual nucleotide sequence comparisons (GAP program of GCG) for the full-length DNA and with 10 regions of ToLCKV (Table 4). Six viruses identified from the BLAST search (ToLCBDV, Tgv-CN, CLCuMV-Fai2[62], ToLCBV-[Ban4], ToLCBV, and PaLCuV) had nucleotide identities between 81 and $86 \%$ across the entire DNA sequence. The highest nucleotide identities for ToLCKV were with ToLCBDV and $\mathrm{Tgv}-\mathrm{CN}$ (85\%). The comparison of the 10 regions of ToLCKV with ToLCBDV and Tgv-CN gave the highest nucleotide identities of $\geq 93 \%$ for the $5^{\prime}$ region of the $V 2$ and $C P$ genes. Similarly, high identities were obtained with $\mathrm{PaLCuV}$ for the $5^{\prime}$ region of the $V 2$ and $C P$ genes and with CLCuMV-Fai2[62] for the $5^{\prime}$ region of the $C P$ gene. This is consistent with the placement of these five viruses in a single clade in the $C P$ gene phylogenetic tree (Fig. 1). Other comparisons of $>90 \%$ nucleotide sequence identities were detected for four other regions of ToLCKV. The $5^{\prime}$ sequence of the $V 2$ gene and the promoter for the $C P$ gene were 98 and $91 \%$ identical, respectively, with those of Tobacco geminivirus from Pakistan isolate P27 (Tgv-PK[P27]); the 5' sequence of the Rep gene was 91 to $95 \%$ identical with that of China rose geminivirus-Pakistan isolate P31 (Crv-PK[P31]), ToLCBV[Ban4], and TYLCV-[IR]. The 5' IR (nucleotides 2609-2666, sequences immediately $5^{\prime}$ of the TATA box) sequence was 91 to 93\% identical with those of Crv-PK[P31] and TYLCV-[IR]. The high nucleotide identities of different regions of ToLCKV with those of other begomoviruses (Table 4) are consistent with the possibility that ToLCKV is a recombinant virus. The results of PLOTSIMILARITY comparisons also support the possibility that ToLCKV is a recombinant virus (Fig. 3). For example, when the full-length sequences of ToLCKV and TYLCV-[IR] were compared, there were high nucleotide identities only for the $5^{\prime}$ region of the Rep gene and the $5^{\prime}$ region of the CR. Likewise, comparison of ToLCKV to ToLCBDV showed that there were high nucleotide identities only for the $V 2$ gene and $5^{\prime}$ region of the $C P$ gene. Results of the Rep gene pairwise comparisons with other begomoviruses (Table 4) indicated that the lineages of the $5^{\prime}$ region and the $3^{\prime}$ region of this gene might be different. When phylogenetic trees were constructed for 26 begomoviruses from the Eastern Hemisphere for the either the $5^{\prime}$ regions (Fig. 4) or the $3^{\prime}$ regions (Fig. 5) of the Rep gene, ToLCKV was placed in different clades. In the $5^{\prime}$ region Rep gene phylogenetic tree, ToLCKV was placed in a clade with ToLCBV-[Ban4] and TYLCV-[IR], whereas when the $3^{\prime}$ region of the Rep gene was used, ToLCKV was in a clade with ToLCBDV and CLCuMv-Fai2[62]. Further evidence of possible recombination within the Rep gene was supported by the GENECONV analysis. Possible recombination regions with $P$ values less than 0.001 were obtained for the $5^{\prime}$ region of the Rep gene from nucleotides 2202 to 2596 (nucleotide numbers correspond to those of ToLCKV) for ToLCKV with TYLCV-[IR] and for nucleotide 2202 to 2528 for ToLCKV with ToLCBV-[Ban4], and for the $3^{\prime}$ region of the Rep gene for nucleotide 1068 to 2120 for ToLCKV with PaLCuV.

\section{DISCUSSION}

The genome of ToLCKV from Bangalore, India, a whiteflytransmitted geminivirus, has been cloned and sequenced. A putative full-length clone (pIND9) was generated from PCR-amplified DNA fragments, and the infectivity of this clone was demonstrated when tomatoes inoculated by particle bombardment developed leaf curl and yellowing symptoms. To date, this is the only tomato-associated begomovirus from Bangalore, India $(4,13$, 21) for which completion of Koch's postulates has been reported. Furthermore, this virus is the only known monopartite begomo-

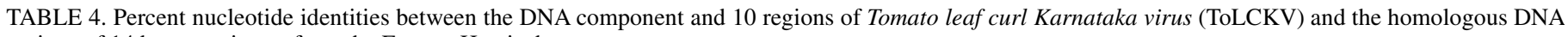
regions of 14 begomoviruses from the Eastern Hemisphere

\begin{tabular}{|c|c|c|c|c|c|c|c|c|c|c|c|}
\hline \multirow[b]{2}{*}{ Begomovirus $^{\mathrm{a}}$} & \multirow[b]{2}{*}{$\mathrm{DNA}^{\mathrm{b}} \mathrm{A}^{\mathrm{b}}$} & \multicolumn{10}{|c|}{ Nucleotide region in monopartite genome of ToLCKV } \\
\hline & & Promoter & $5^{\prime} V 2$ & $5^{\prime} C P$ & $3^{\prime} C P$ & $3^{\prime} R E n$ & $3^{\prime} \operatorname{Tr} A P$ & $3^{\prime} \operatorname{Rep}$ & $5^{\prime} \mathrm{Rep}$ & $5^{\prime} \mathrm{CR}$ & $3^{\prime} \mathrm{S}-\mathrm{L}$ \\
\hline ToLCBDV & 85 & 63 & 94 & 95 & 84 & 88 & 90 & 89 & 80 & 60 & 67 \\
\hline $\mathrm{Tgv}-\mathrm{CN}$ & 85 & 62 & 93 & 97 & 83 & 81 & 87 & 85 & 84 & 55 & 65 \\
\hline CLCuMV-Fai2[62] & 84 & 64 & 85 & 98 & 84 & 90 & 92 & 86 & 76 & 48 & 82 \\
\hline ToLCBV-[Ban4] & 84 & 54 & 77 & 79 & 89 & 88 & 91 & 79 & 91 & 86 & 49 \\
\hline ToLCBV & 82 & 55 & 76 & 78 & 90 & 89 & 91 & 82 & 79 & 53 & 46 \\
\hline PaLCuV & 82 & 85 & 94 & 97 & 84 & 86 & 89 & 85 & 59 & 50 & 49 \\
\hline ToLCMV & 78 & 51 & 71 & 81 & 73 & 67 & 80 & 83 & 86 & 72 & 55 \\
\hline TYLCV-IR & 78 & 56 & 75 & 78 & 71 & 64 & 78 & 77 & 93 & 93 & 65 \\
\hline ToLCNdV & 77 & 50 & 75 & 82 & 75 & 66 & 75 & 80 & 85 & 86 & 48 \\
\hline ToLCTWV & 77 & 50 & 75 & 82 & 75 & 66 & 80 & 80 & 85 & 86 & 48 \\
\hline BYVV & 75 & 45 & 71 & 83 & 81 & 70 & 76 & 77 & 72 & 48 & 89 \\
\hline Crgv-PK[P31] & - & 43 & 73 & - & - & - & - & - & 95 & 91 & 89 \\
\hline Tgv-PK[27] & - & 91 & 98 & - & - & - & - & - & 80 & 60 & 55 \\
\hline ToLCSadV-[Ban1] & - & - & - & - & - & - & - & - & - & 50 & 53 \\
\hline
\end{tabular}

a Begomovirus acronyms are provided in Table 1 .

b The DNA-A or the monopartite component.

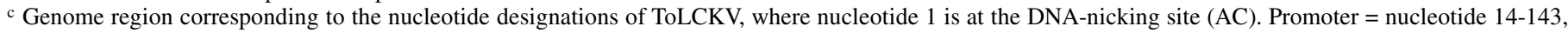
$5^{\prime}$ end of capsid protein $(C P)$ gene promoter region to start of $V 2$ gene; $3^{\prime} V 2=$ nucleotide $144-303,5^{\prime}$ end of the $V 2$ gene from start codon to start codon for $C P$ gene; $5^{\prime} C P=$ nucleotide $304-544,240$ nucleotides of the $5^{\prime}$ end of $C P$ gene; $3^{\prime} C P=$ nucleotide $545-1074,3^{\prime}$ end of the $C P$ gene; $3^{\prime} R E n=$ nucleotide $1071-1215,3^{\prime}$ end of the $R E n$ gene from its stop codon to the stop codon for the $\operatorname{Tr} A P$ gene; $3^{\prime} \operatorname{Tr} A P=$ nucleotide $1216-1522,3^{\prime}$ end of the $\operatorname{Tr} A P$ gene from its stop codon to the stop codon of the replication-associated protein (Rep) gene; $3^{\prime}$ Rep $=$ nucleotide $1523-2157,3^{\prime}$ end of the Rep gene; $5^{\prime}$ Rep $=$ nucleotide $2158-2608,5^{\prime}$ end of the Rep gene; $5^{\prime}$ common region $(\mathrm{CR})=$ nucleotide $2609-2666,5^{\prime}$ end of the intergenic region (IR) to the TATA box; $3^{\prime} \mathrm{S}-\mathrm{L}=$ nucleotide 2676-2740, the region in the $5^{\prime}$ IR corresponding to the $5^{\prime}$ of the TATA box to the start of the stem-loop (S-L) motif. Shared cells have $90 \%$ nucleotide identity or greater with ToLCKV. - indicates sequence not available for this begomovirus. 
virus that is sap-transmissible $(7,15,23)$. Whiteflies readily transmitted the virus to healthy tomatoes from tomatoes infected with ToLCKV after particle bombardment with pIND9. On the basis of these results and the lack of a hybridization signal from the original dried tissue from tomatoes with leaf curl symptoms in dot blot analysis at low stringency with the DNA-B of Tomato yellow leaf curl Thailand virus (TYLCTHV) (3) (unpublished data), it can be concluded that the single DNA component in pIND9 contains all the elements required for viral replication, symptom development, and insect transmission. The genome organization of ToLCKV is similar to that of other Eastern Hemisphere monopartite begomoviruses from Australia (7), Israel (23), and Sardinia (15), but different from that of the bipartite begomoviruses, TYLCTHV from Thailand $(3,28)$ and ToLCNdV from northern India (24). In addition, ToLCKV is considered to be distinct from the other three tomato-associated begomoviruses from Bangalore, India (4,13,21). ToLCSadV-[Ban1] from Bangalore was the first begomovirus from India to be partially sequenced (4) (L11746, L12738, and L12739), and it is not closely related to ToLCKV as indicated by 75 and $65 \%$ nucleotide identities between the Rep genes and the $5^{\prime}$ IRs of ToLCKV and Tomato leaf curl Sardinia virus (ToLCSardV)-[Ban1], respectively. The nucleotide comparisons of the full-length sequence of ToLCKV to those of ToLCBV[Ban4] (21), ToLCBV (13), and ToLCBDV had $<86 \%$ identities, so according to the convention that begomoviruses differing by more than $10 \%$ are species (16), ToLCKV is a distinct species.

Recombination among members of the begomoviruses has been well documented for field isolates $(12,25)$, and by laboratory

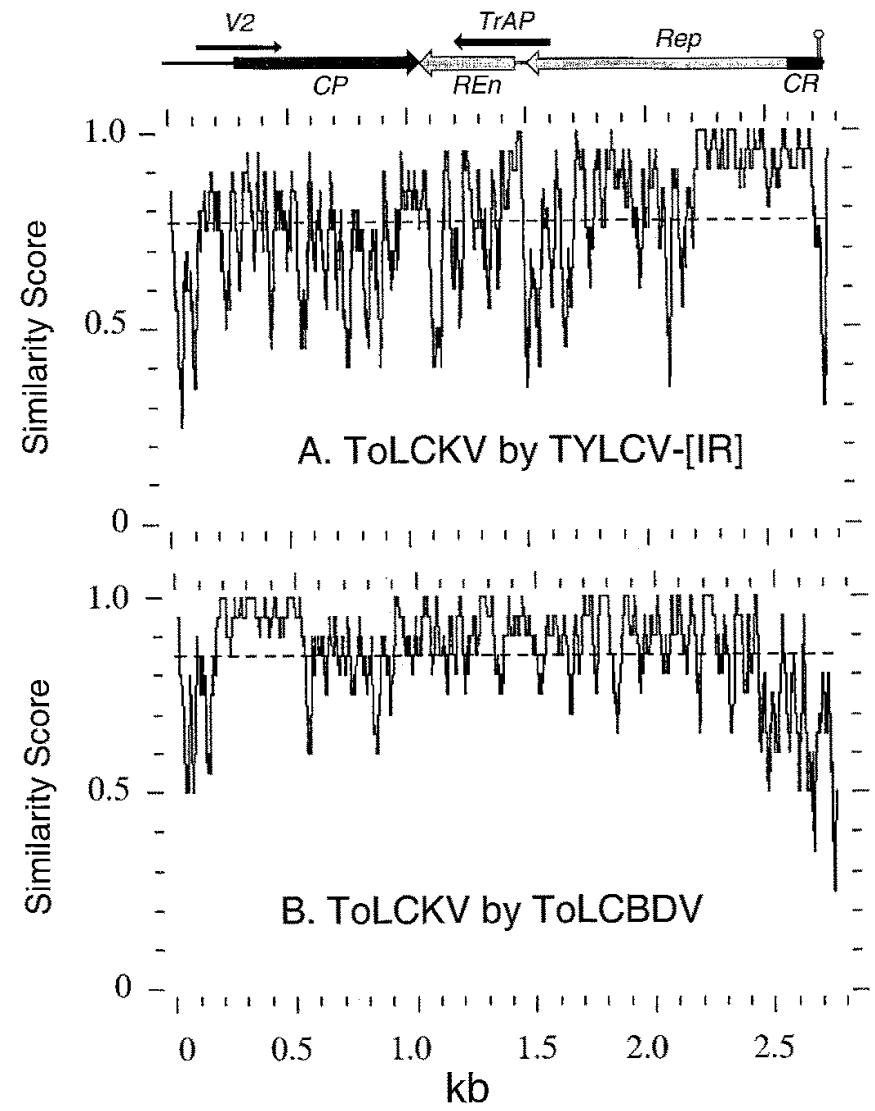

Fig. 3. PLOTSIMILARITY diagrams (scanning window $=20$ ) comparing the full-length sequences of A, Tomato leaf curl Karnataka virus (ToLCKV) and Tomato yellow leaf curl virus-[Iran] (TYLCV-[IR]) and B, ToLCKV and Tomato leaf curl Bangladesh virus (ToLCBDV). Positions of the regions in the genomes are represented at the top of the figure with the stem-loop motif at the right of this drawing. The nucleotide positions of the genome at the bottom of the figure are in kilobases $(\mathrm{kb})$. The horizontal broken line is the mean identity between the two sequences compared. studies with pseudorecombinants of Western Hemisphere bipartite begomoviruses (14). It appears that either ToLCKV is a recombinant virus or that its progenitors have contributed sequences to other begomoviruses in Asia. A similar conclusion was suggested by Sanz et al. (33) and Navas-Castillo et al. (22). Full-length DNA-A sequences are available for three tomato-associated begomoviruses from Bangalore, ToLCBV, ToLCBV-[Ban4], and ToLCKV. In the phylogenetic trees for the $C P$ and Rep genes (Figs. 1 and 2), ToLCBV and ToLCBV-[Ban4] are placed in the same clade, and the complete sequences of these two viruses are $91 \%$ identical. The nucleotide sequences of the $5^{\prime}$ region of the Rep gene and adjacent $5^{\prime}$ IR of ToLCKV had high identities with homologous sequences of ToLCBV-[Ban4] (91 and 86\%, respectively) but considerably lower identities with those of ToLCBV (79 and 53\%, respectively). One explanation for this is that a recombination event occurred between ToLCKV and ToLCBV or their progenitors such that the $5^{\prime}$ region of the Rep gene and adjacent $5^{\prime}$ IR of ToLCKV recombined with ToLCBV to create ToLCBV-[Ban4], and then the three viruses (ToLCKV and ToLCBV and the recombinant virus ToLCBV-[Ban4]) continued to evolve via mutations to arrive at the current divergence. Simi-

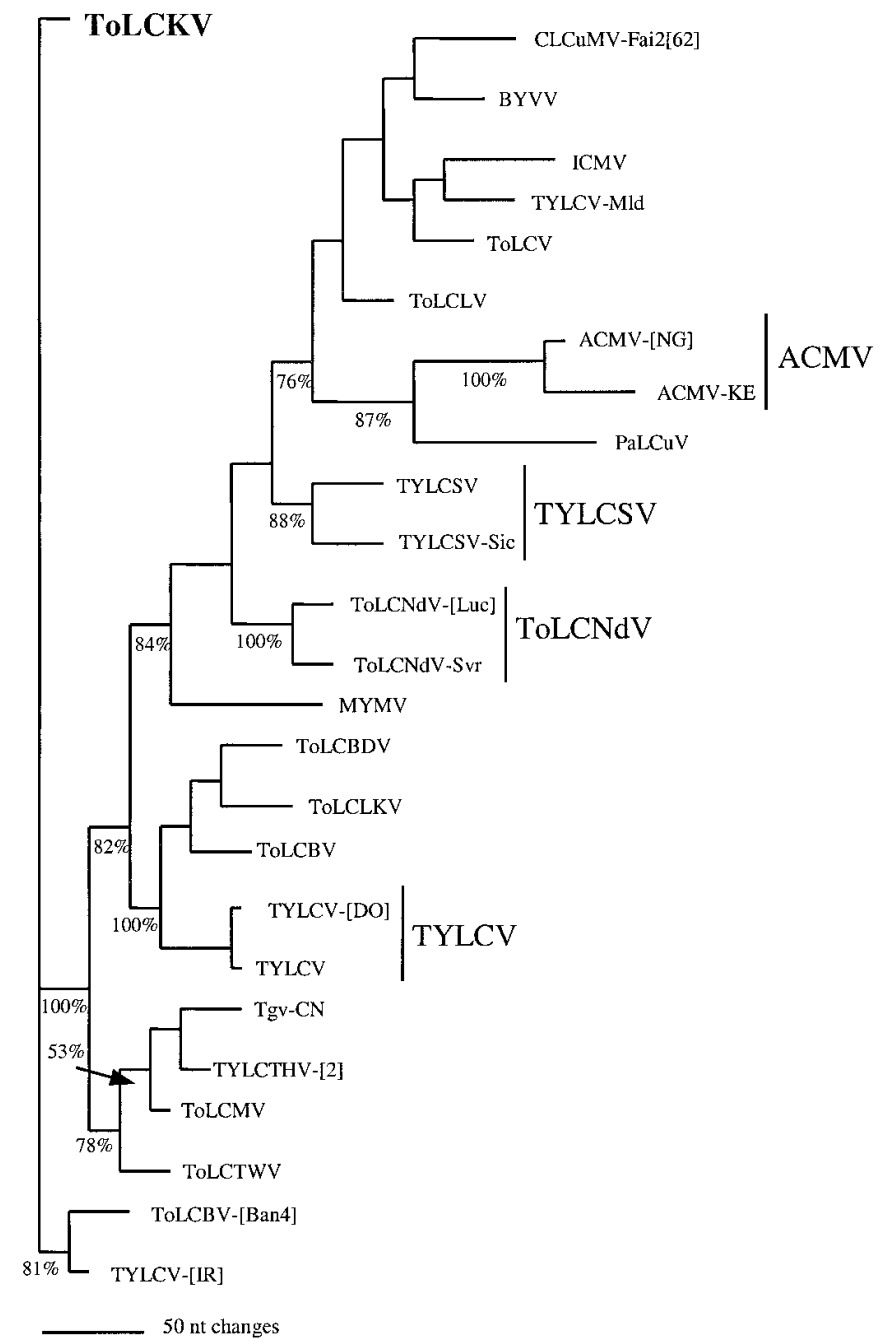

Fig. 4. Phylogenetic tree showing the relationship of Tomato leaf curl Karnataka virus (ToLCKV) isolate Bangalore 2 with 26 begomoviruses based on the alignment of nucleotide sequences of the $5^{\prime}$ region ( $\mathrm{N}$ terminus) of the replication-associated protein gene (nucleotides 2158 to 2608). Tree was created by PAUP program version 3.1. The percentage of trees having the given branch is shown below the horizontal line. Vertical distances are arbitrary, and the horizontal distances are in proportion to the number of nucleotide differences between branch nodes. Abbreviations and GenBank accession numbers of viruses are provided in Table 1. 
larly, it is evident that TYLCV-[IR] from Iran is a recombinant virus between the Eastern Mediterranean TYLCV (23) and the 5' region of the Rep gene and adjacent $5^{\prime}$ IR sequences of ToLCKV or a ToLCKV-like virus (Figs. 3 and 4; Table 4). Further evidence for recombination in the $5^{\prime}$ region of the Rep gene among ToLCKV, TYLCV-[IR], and ToLCBV-[Ban4] was supported by the statistical analysis with GENECONV.

BLAST searches for begomoviruses with sequences nearly identical to those of ToLCKV indicated that ToLCKV appears to share sequences with a complex of begomoviruses from Pakistan (33). This conclusion is based upon the high percent nucleotide identities of ToLCKV for (i) the $5^{\prime}$ region of the Rep gene (95\%) and adjacent $5^{\prime}$ IR (91\%) with Crgv-PK[P31] (AJ270864) from China rose (Hibiscus rosa-sinensis), and (ii) the promoter of the $C P$ gene (91\%) and V2 gene (98\%) with Tgv-PK[P27] (AJ270861) from tobacco (Table 4). It is unfortunate that complete sequences are not available for Tgv-PK[P27] and Crgv$\mathrm{PK}[\mathrm{P} 31]$, because these two viruses have the highest nucleotide identities with certain regions of ToLCKV.

Our sequence analyses support the conclusion made by others $(12,22,36)$ that several distinct lineages exist for the tomatoassociated begomoviruses from the Eastern Hemisphere. The most

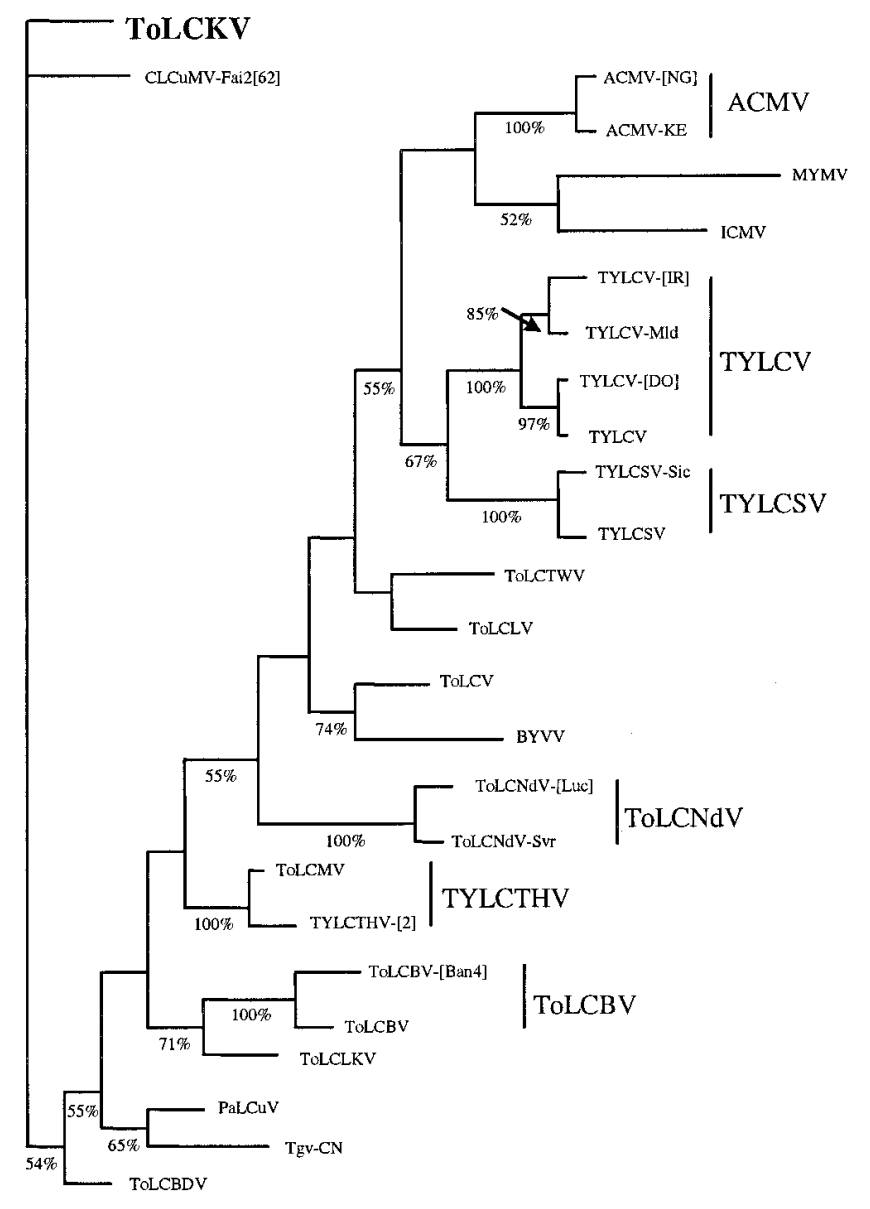

50 nt changes

Fig. 5. Phylogenetic tree showing the relationship of Tomato leaf curl Karnataka virus (ToLCKV) isolate Bangalore 2 with 26 begomoviruses based on the alignment of nucleotide sequences of the $3^{\prime}$ region (C terminus) of the replication-associated protein gene (nucleotides 1523 to 2157). Tree was created by PAUP program version 3.1. The percentage of trees having the given branch is shown below the horizontal line. Vertical distances are arbitrary, and the horizontal distances are in proportion to the number of nucleotide differences between branch nodes. Abbreviations and GenBank accession numbers of viruses are provided in Table 1. evident lineages (Figs. 1 and 2) are for (i) ToLCMV and TYLCTHV, (ii) the western Mediterranean isolates (TYLCSV), (iii) the eastern Mediterranean isolates or strains of TYLCV, (iv) the ToLCBV isolates from southern India, and (v) the northern Indian isolates of ToLCNdV. The tomato-associated begomoviruses that appear to have undergone recombination events include ToLCKV, ToLCBDV, ToLCBV-[Ban4], TYLCV-[IR], and the mild strain of TYLCV. The latter virus has the $5^{\prime}$ region of its Rep gene in the clade with Indian cassava mosaic virus and the $3^{\prime}$ region of its Rep gene in the clade with isolates of TYLCV (Figs. 4 and 5). Our results support the conclusion made by others $(12,14,22,25,33)$ that recombination is an important mechanism associated with the origin of new begomoviruses.

\section{ACKNOWLEDGMENTS}

This research was supported, in part, by the College of Agricultural and Life Sciences, University of Wisconsin-Madison, and by grants to D. P. Maxwell from Asgrow Seed Co., Peto Seed Co., and the Asian Vegetable Research and Development Center, and by a scholarship from the Royal Thai Government to O. Chatchawankanphanich. This research was, in part, a collaboration among S. K. Green from the Asian Vegetable Research and Development Center (AVRDC), Tainan, Taiwan; S. J. Singh from the Indian Institute of Horticultural Research, Bangalore, India; and D. P. Maxwell from the University of Wisconsin-Madison. We thank B.-T. Chiang for obtaining the first clone of ToLCV from Bangalore (Bangalore 1 isolate); M. D. Maxwell, M. K. Nakhla, and J. L. Potter for critical review of the manuscript; M. D. Maxwell for biolistic inoculation of tomatoes and preparation of figures; D. R. Russell for the use of the electric discharge particle acceleration apparatus at Agracetus Inc.; and P. Mehta for assistance with the whitefly transmission experiments. The 'Geneva 80' tomato seeds were provided by R. Providenti, Cornell University, Geneva, NY.

\section{LITERATURE CITED}

1. Altschul, S. F., Madden, T. L., Schäffer, A. A., Zhang, J., Zhang, Z., Miller, W., and Lipman, D. J. 1997. Gapped BLAST and PSI-BLAST: A new generation of protein database search programs. Nucleic Acids Res. 25:3389-3402.

2. Antignus, Y., and Cohen, S. 1994. Complete nucleotide sequence of an infectious clone of a mild isolate of tomato yellow leaf curl virus (TYLCV). Phytopathology 84:707-712.

3. Attathom, S., Chiemsombat, P., Kositratana, W., and Sae-Ung, N. 1994. Complete nucleotide sequence and genome analysis of bipartite tomato yellow leaf curl virus in Thailand. Kasetsart J. Soc. Sci. 28:632-639.

4. Chatchawankanphanich, O., Chiang, B.-T., Green, S. K., Singh, S. J., and Maxwell, D. P. 1993. Nucleotide sequence of a geminivirus associated with tomato leaf curl from India. Plant Dis. 77:1168.

5. Czosnek, H., Ber, R., Antignus, Y., Cohen, S., Navot, N., and Zamir, D. 1988. Isolation of tomato yellow leaf curl virus, a geminivirus. Phytopathology 78:508-512.

6. Dellaporta, S. L., Wood, J., and Hicks, J. B. 1983. A plant DNA minipreparation: Version II. Plant Mol. Biol. Rep. 1:19-21.

7. Dry, I. B., Rigden, J. E., Krake, L. R., Mullineaux, P. M., and Rezaian, M. A. 1993. Nucleotide sequence and genome organization of tomato leaf curl geminivirus. J. Gen. Virol. 74:147-151.

8. Fauquet, C. M., Maxwell, D. P., Gronenborn, B., and Stanley, J. 2000. Revised proposal for naming geminiviruses. Arch. Virol. 145:17431761.

9. Gilbertson, R. L., Faria, J. C., Hanson, S. F., Morales, F. J., Ahlquist, P., Maxwell, D. P., and Russell, D. R. 1991. Cloning of the complete DNA genomes of four bean-infecting geminiviruses and determining their infectivity by electric discharge particle acceleration. Phytopathology 81:980-985.

10. Green, S. K., and Kalloo, G. 1994. Leaf curl and yellowing viruses of pepper and tomato: An overview. Asian Veg. Res. Dev. Cent. Tech. Bull. 21.

11. Hanley-Bowdoin, L., Settlage, S. B., Orozco, B. M., Nagar, S., and Robertson, D. 1999. Geminiviruses: Models for plant DNA replication, transcription, and cell cycle regulation. Crit. Rev. Plant Sci. 18:71-106.

12. Harrison, B. D., and Robinson, D. J. 1999. Natural genomic and antigenic variation in whitefly-transmitted geminiviruses (begomoviruses). Annu. Rev. Phytopathol. 37:369-398.

13. Hong, Y. G., and Harrison, B. D. 1995. Nucleotide sequences from tomato leaf curl viruses from different countries: Evidence for three geo- 
graphically separate branches in evolution of the coat protein of whitefly-transmitted geminiviruses. J. Gen. Virol. 76:2043-2049.

14. Hou, Y.-M., and Gilbertson, R. L. 1996. Increased pathogenicity in a pseudorecombinant bipartite geminivirus correlates with intermolecular recombination. J. Virol. 70:5430-5436.

15. Khey-Pour, A., Bendahmane, M., Matzeit, V., Accoto, G. P., Crespi, S., and Gronenborn, B. 1991. The tomato yellow leaf curl virus from Sardinia (TYLCV-S) has a single genetic component. Nucleic Acids Res. 19:6763-6769.

16. Mayo, M. A., and Pringle, C. R. 1998. Virus taxonomy-1997. J. Gen. Virol. 79:649-657.

17. McCabe, D. E., Swain, W. F., Martinell, B. J., and Christou, P. 1988. Stable transformation of soybean (Glycine max) by particle acceleration. Bio/Technology 6:923-926.

18. Mehta, P., Wyman, J. A., Nakhla, M. K., and Maxwell, D. P. 1994. Transmission of tomato yellow leaf curl geminivirus by Bemisia tabaci (Homoptera: Aleyrodidae). J. Econ. Entomol. 87:1291-1297.

19. Mullineaux, P. M., Rigden, J. E., Dry, I. B., Krake, L. R., and Rezaian, M. A. 1993. Mapping of the polycistronic RNAs of tomato leaf curl geminivirus. Virology 193:414-423.

20. Muniyappa, V., Swanson, M. M., Duncan, G. H., and Harrison, B. D. 1991. Particle purification, properties and epitope variability of Indian tomato leaf curl geminivirus. Ann. Appl. Biol. 118:595-604.

21. Muniyappa, V., Venkatesh, H. M., Ramappa, H. K., Kulkarni, R. S., Zeidan, M., Tarba, C.-Y., Ghanim, M., and Czosnek, H. 2000. Tomato yellow leaf curl virus from Bangalore (ToLCV-Ban4): Sequence comparison with Indian ToLCV isolates, detection in plants and insects, and vector relationships. Arch. Virol. 145:1583-1598.

22. Navas-Castillo, J., Sánchez-Campos, Noris, E., Louro, D., Accotto, G. P., and Moriones, E. 2000. Natural recombination between tomato yellow leaf curl virus-Is and tomato leaf curl virus. J. Gen. Virol. 81:2797-2801.

23. Navot, N., Pichersky, E., Zeidan, M., Zamir, D., and Czosnek, H. 1991. Tomato yellow leaf curl virus: A whitefly-transmitted geminivirus with a single genomic component. Virology 185:151-161.

24. Padidam, M., Beachy, R. N., and Fauquet, C. M. 1995. Tomato leaf curl geminivirus from India has a bipartite genome and coat protein is not essential for infectivity. J. Gen. Virol. 76:26-35.

25. Padidam, M., Sawyer, S., and Fauquet, C. 1999. Possible emergence of new geminiviruses by frequent recombination. Virology 265:218-225.

26. Polston, J. E., and Anderson, P. K. 1997. The emergence of whiteflytransmitted geminiviruses in the Western Hemisphere. Plant Dis. 81:1358-1369.

27. Reddy, K. S., Yaraguntaiah, R. C., and Sastry, K. S. 1981. Strains of leaf curl virus of tomato in India. J. Plant Dis. Prot. 88:400-404.

28. Rochester, D. E., Kositratana, W., and Beachy, R. N. 1990. Systemic movement and symptom production following agroinoculation with a single DNA of tomato yellow leaf curl geminivirus (Thailand). Virology 178:520-526.

29. Rojas, M. R., Gilbertson, R. L., Russell, D. R., and Maxwell, D. P. 1993. Use of degenerate primers in the polymerase chain reaction to detect whitefly-transmitted geminiviruses. Plant Dis. 77:340-347.

30. Rybicki, E., Briddon, R. W., Brown, J. E., Fauquet, C. M., Maxwell, D. P., Harrison, B. D., Markham, P. G., Bisaro, D. M., Robinson, D., and Stanley, J. 1999. Family Geminiviridae. Pages 285-297 in: Virus Taxonomy. Seventh Report of the International Committee on Taxonomy of Viruses. M. H. V. van Regenmortel, C. M. Fauquet, D. H. L. Bishop, E. B. Crsten, M. K. Estes, S. M. Lemon, J. Maniloff, M. A. Mayo, D. J. McGeoch, C. R. Pringle, and R. B. Wickner, eds. Academic Press, San Diego.

31. Sambrook, J., Fritsch, E. F., and Maniatis, T. 1989. Molecular Cloning: A Laboratory Manual. 2nd ed. Cold Spring Harbor Laboratory, Cold Spring Harbor, NY.

32. Sanger, F., Nicklen, S., and Coulson, A. R. 1977. DNA sequencing with chain terminating inhibitors. Proc. Natl. Acad. Sci. USA 74:5463-5467.

33. Sanz, A. I., Fraile, A., García-Arenal, F., Zhou, X., Robinson, D. J., Khalid, S., Butt, T., and Harrison, B. D. 2000. Multiple infection, recombination and genome relationships among begomovirus isolates found in cotton and other plants in Pakistan. J. Gen. Virol. 81:1839-1849.

34. Townsend, R., Stanley, J., Curson, S. J., and Short, M. N. 1985. Major polyadenylated transcripts of cassava latent virus and location of the gene encoding protein. EMBO J. 4:33-37.

35. Vasudeva, R. S., and Sam Raj, J. 1948. A leaf curl disease of tomato. Phytopathology 38:364-369.

36. Zeidan, M., Green, S. K., Maxwell, D. P., Nakhla, M. K., and Czosnek, H. 1998. Molecular analysis of whitefly-transmitted tomato geminiviruses from Southeast and East Asia. Trop. Agric. Res. Exten. 1:107-115. 